\title{
Vladimir Nikolaevich Losev Turns Fifty
}

DOI: $10.1134 / \mathrm{S} 106193481110008 \mathrm{X}$

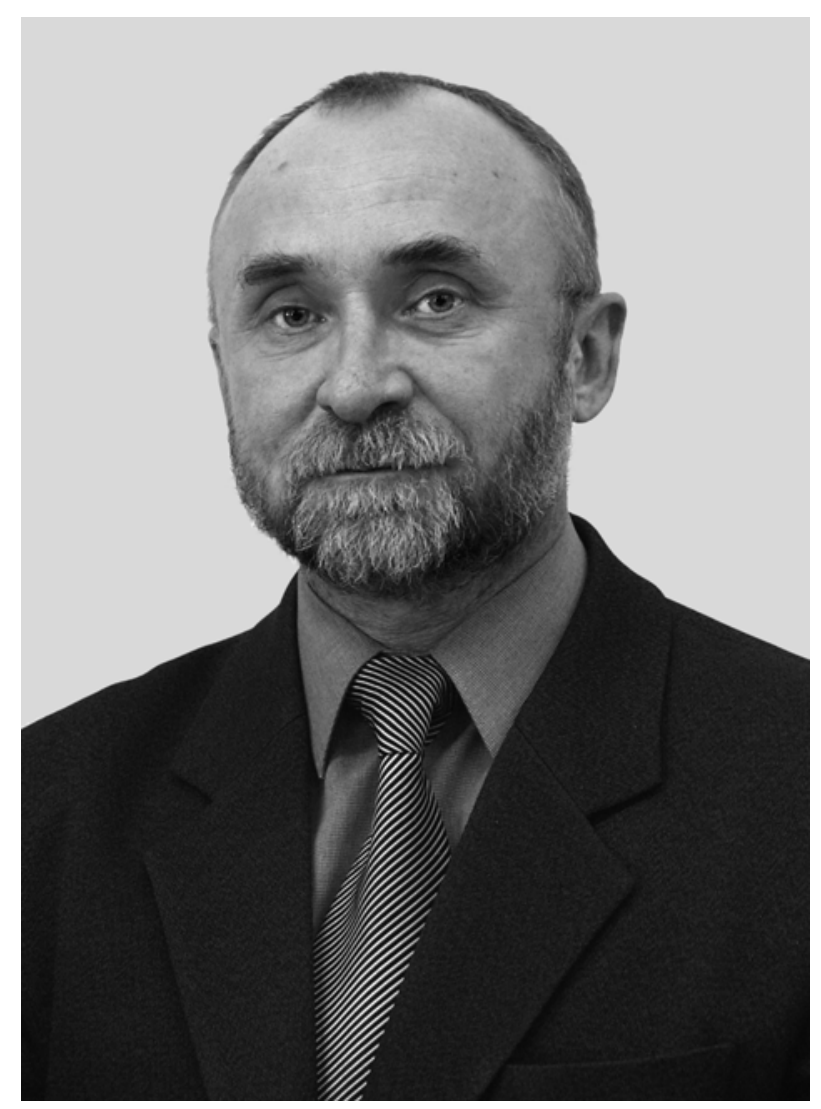

October 12, 2011 marks the 50th birthday of Vladimir Nikolaevich Losev, Doctor of Chemistry, Professor, Director of the Crystal Research Engineering Center (Krasnoyarsk), and Head of the Laboratory of Applied Chemistry of the same center.

In 1984, Losev graduated from the Department of Biology and Chemistry of Krasnoyarsk State University. After graduation from the graduate courses of the Department of Chemistry, Moscow State University, in 1991, Losev defended his candidate's dissertation "Luminescence of iridium(III) and rhodium(III) Complexes with 2,2'-bipyridil and Its Analytical
Applications" and in 2007, his doctoral dissertation "Silicas Chemically Modified with Sulfur-Containing Groups for the Preconcentration, Separation, and Determination of Noble and Nonferrous Metals." In 2009 , he was given the title of professor. Starting from 1992, Losev has worked at the State Crystal Institute, where he traveled the route from senior researcher to director. In 1992, he organized a laboratory, which he now heads.

Professor Losev conducts research into the application of adsorbents of various nature for the extraction, preconcentration, and determination of noble and nonferrous metals. The main cycle of works was devoted to the use of chemically modified silicas for sorption preconcentration, separation, and subsequent spectroscopic determination of elements. Professor Losev supervises research into the synthesis of adsorbents based on phytogenic materials chemically modified with various functional groups of inorganic oxides modified with polymeric polyamines and sulfo derivatives of organic reagents. The adorbents are used in sorption-spectroscopic and test methods to determine noble and nonferrous metals in objects of various composition. In recent years, studies have been conducted on determining chemical elements and their speciation in biological objects.

Professor Losev supervised 7 candidate's dissertations; published more than 80 articles and 40 inventor's certificates and patents of the Russian Federation; and has given a number of presentations at conferences of various levels. $\mathrm{He}$ is a member of the Scientific Council on Analytical Chemistry of the Russian Academy of Sciences, actively cooperates with experts from various scientific organizations and higher educational institutions, and is an authority among colleagues and pupils.

The staff and editorial board of Zhurnal Analiticheskoi Khimii, colleagues, and friends warmly congratulate Vladimir Nikolaevich on his birthday and wish him further creative successes, sound health, and a cheerful attitude. 